\title{
Oral corticosteroids for exacerbations of chronic obstructive pulmonary disease
}

\author{
J A Wedzicha \\ Academic Respiratory Medicine, St Bartholomew's and Royal London School of \\ Medicine and Dentistry, St Bartholomew's Hospital, London EC1A 7BE, UK
}

Introductory articles

Oral corticosteroids in patients admitted to hospital with exacerbations of chronic
obstructive pulmonary disease: a prospective randomised controlled trial

L Davies, RM Angus, PMA Calverley

Background. The role of oral corticosteroids in treating patients with exacerbations of chronic obstructive pulmonary disease (COPD) remains contentious. We assessed in a prospective, randomised, doubleblind, placebo-controlled trial the effects of oral corticosteroid therapy in patients with exacerbations of COPD requiring hospital admission. Methods. We recruited patients with non-acidotic exacerbations of COPD who were randomly assigned oral prednisolone $30 \mathrm{mg}$ once daily $(n=29)$ or identical placebo $(n=27)$ for 14 days, in addition to standard treatment with nebulised bronchodilators, antibiotics, and $\&$ oxygen. We did spirometry and recorded symptom scores daily in inpatients. Time to discharge and withdrawals were noted in each group. We recalled patients at 6 weeks to repeat spirometry and collect data on subsequent exacerbations and treatment. Hospital stay was analysed by intention to treat and

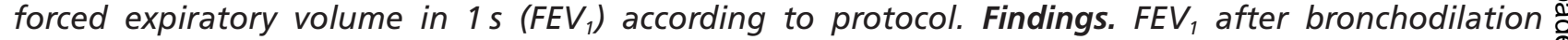
increased more rapidly and to a greater extent in the corticosteroid-treated group: percentage predicted $\mathbb{D}$ FEV 1 after bronchodilation rose from $25.7 \%(95 \%$ Cl 21.0-30.4) to 32.2\% (27.3-27.1) in the placebo group ( $p<0.0001)$ compared with $28.2 \%(23.5-32.9)$ to $41.5 \%(35.8-47.2)$ in the corticosteroid-treated group $(p<0.0001)$. Up to day 5 of hospital stay, FEV 1 after bronchodilation increased by $90 \mathrm{~mL}$ daily (50.8-129.2) and by $30 \mathrm{~mL}$ daily (10.4-49.6) in the placebo group $(p=0.039)$. Hospital stays were shorter in the corticosteroid-treated group. Groups did not differ at 6-week follow-up. Interpretation. These data provide evidence to support the current practice of prescribing low-dose oral corticosteroids to $x$ all patients with non-acidotic exacerbations of COPD requiring hospital admission. (Lancet 1999;354: 456-60)

\section{Effect of systemic glucocorticoids on exacerbations of chronic obstructive pulmonary disease}

DE Niewoehner, ML Erbland, RH Deupree, D Collins, NJ Gross, RW Light, P Anderson, NA Morgan for the Department of Veterans Affairs Cooperative Study Group

Background and Methods. Although their clinical efficacy is unclear and they may cause serious adverse $\overbrace{0}^{2}$ effects, systemic glucocorticoids are a standard treatment for patients hospitalized with exacerbations of chronic obstructive pulmonary disease (COPD). We conducted a double-blind, randomized trial of $\stackrel{+}{\rightarrow}$ systemic glucocorticoids (given for two or eight weeks) or placebo, in addition to other therapies, for $\frac{0}{0}$ exacerbations of COPD. Most other care was standardized over the six-month period of follow-up. The $\stackrel{\vec{\nabla}}{\stackrel{8}{8}}$ primary end point was treatment failure, defined as death from any cause or the need for intubation $\stackrel{\square}{2}$ and mechanical ventilation, readmission to the hospital for COPD, or intensification of drug therapy. Results. Of 1840 potential study participants at 25 Veterans Affairs medical centers, 271 were eligible 8 for participation and were enrolled; 80 received an eight-week course of glucocorticoid therapy, $80 \stackrel{0}{5}$ received a two-week course, and 111 received placebo. About half the potential participants were $\stackrel{0}{\exists}$ ineligible because they had received systemic glucocorticoids in the previous 30 days. Rates of treatment failure were significantly higher in the placebo group than in the two glucocorticoid groups combined at 30 days (33 percent vs. 23 percent, $p=0.04$ ) and at 90 days (48 percent vs. 37 percent, $p=0.04$ ). Systemic glucocorticoids (in both groups combined) were associated with a shorter initial hospital stay 
(8.5 days, vs. 9.7 days for placebo; $p=0.03$ ) and with a forced expiratory volume in one second that was about 0.10 liter higher than that in the placebo group by the first day after enrollment. Significant treatment benefits were no longer evident at six months. The eight-week regimen of therapy was not $\vec{\sigma}$ superior to the two-week regimen. The patients who received glucocorticoid therapy were more likely $\underset{x}{\stackrel{x}{*}}$ to have hyperglycemia requiring therapy than those who received placebo (15 percent vs. 4 percent, $\overrightarrow{\nexists \vec{B}}$ $p=0.002$ ). Conclusions. Treatment with systemic glucocorticoids results in moderate improvement in clinical outcomes among patients hospitalized for exacerbations of COPD. The maximal benefit is $\frac{0}{\sigma}$ obtained during the first weeks of therapy. Hyperglycemia of sufficient severity to warrant treatment $\frac{\vec{m}}{\vec{p}}$ is the most frequent complication. (N Engl J Med 1999;340:1941-7)

Exacerbations of chronic obstructive pulmonary disease (COPD) are an important cause of morbidity and mortality in patients with COPD. Some patients are prone to frequent exacerbations that lead to hospital admissions which have considerable impact on activities of daily living and health status andelines for the management of COPD, including exacerbations, advise on the use of bronchodilators, steroids, antibiotics, or oxygen therapy if required.

Only $10-15 \%$ of patients with stable COPD show a spirometric response to oral corticosteroid $\$$ and, unlike asthma, steroids seem to have liftle effect on airway inflammatory markers in COPD. However, in contrast to asthma, , until recently there has been little evidence for benefit from oral corticosteroids during COPD exacerbations, although steroids are widely used in their treatment. There is little information available on determinants of exacerbation severity, although this may be important when selecting patients for treatment with steroids. Some patients who are prone to frequent exacerbations may require multiple courses of steroids each year and may be prone to side effects such as steroid induced myopathy and osteoporosis. Thus, more evidence is required for the benefit of steroid treatment for COPD exacerbations.

\section{Epidemiology of COPD exacerbations}

Descriptions of COPD exacerbations have concentrated mainly on studies of exacerbations requiring hospital admission, although mostare treated in the community. Seemungal and colleague ${ }^{2}$ followed a cohort of patients with moderate to severe COPD in East London, UK, with daily diary cards and peak flow readings. Patients were asked to report exacerbations as soon as possible after onset of symptoms. They found that about $50 \%$ of exacerbations went unreported to the research team, despite considerable encouragement, and were only subsequently diagnosed from diary cards. However, there were no major differences in symptoms or physiological parameters between reported and unreported exacerbations. ${ }^{2}$ Patients with COPD are accustomed to frequent changes in symptoms and so may tend to under-report exacerbations to physicians. These patients also have high levels of anxiety and depression and may accept their situation ${ }^{9}$ The high degree of under-reporting of exacerbations suggests that many are initially undertreated in the community, possibly leading to the high admission and readmission rates characteristic of COPD.

In a further prospective analysis of 504 exacerbations, where daily monitoring was performed, falls in peak flow and forced expiratory volume in one second $\left(\mathrm{FEV}_{1}\right)$ were generally small and not useful in predicting exacerbations. ${ }^{10}$ However, larger falls in peak flow were associated with symptoms of dyspnoea, the presence of colds, or were related to longer recovery time from $\overrightarrow{\vec{\omega}}$ exacerbations. Symptoms of dyspnoea, the common cold, sore throat and cough increased significantly dur- 을 ing the prodromal phase and this suggests a causal role $\underset{\times}{\times}$ for respiratory viruses during exacerbations. Ex- of acerbations associated with symptoms of the common is cold and so with upper respiratory viruses are likely to be more severe and may require treatment with $\left.\right|^{-}$ corticosteroids in addition to bronchodilators and anti- $\overrightarrow{i n}$ biotics. The median time for recovery of peak flow was $\underset{\mathrm{W}}{ }$ six days, and seven days for symptoms, but at 35 days 을 peak flow had returned to normal in only $75 \%$ of exacerbations, whilst at 91 days $7.1 \%$ of exacerbations had not returned to baseline lung function. Recovery took longer in the presence of increased dyspnoea or $\stackrel{\infty}{\oplus}$ symptoms of a common cold, again suggesting that $N$ these associations lead to more severe exacerbations. ${ }^{10} \circ$ There are some differences between asthmatic and COPD exacerbations. Changes observed in peak flow were smaller in COPD than those seen in asthma, although the average duration of an asthmatic exacerbation was longer at 9.6 days $\left.{ }^{1}\right|_{12}$

\section{Causes of COPD exacerbations}

An understanding of the causes of COPD exacerbations is important to direct treatment and appropriate prevention. COPD exacerbations are associated with respiratory infection. They are frequently triggered by upper respiratory tract infections and these are more 3 common in the winter months when there are more respiratory viral infections in the community. Patients may also be more prone to exacerbations during the winter as their lung function shows small butsignificant falls with reduction in outdoor temperature 13 Patients $\frac{D}{2}$ with COPD have increased hospital admission rates when increased environmental pollution occurs. During o the pollution episode in the UK in December $1991 \mathrm{~N}$ mortality from COPD was increased, as were hospital స్ట admission rates in elderly COPD patients. ${ }^{14}$

Airway bacterial colonisation has been found in approximately $30 \%$ of patients with COPD, which has been shown to be related to the degree of airflow $\stackrel{\text { ? }}{\rightarrow}$ obstruction and current cigarette smoking.$^{1}{ }^{16}$ Although bacteria such as Haemophilus influenzae and Streptococcus $\stackrel{\vec{D}}{\mathbb{D}}$ pneumoniae have been associated with COPD exacerbations, only some studies have shown increased $\cong$ bacterial counts whilst others have not. $\left.{ }^{1}\right|^{18}$ Other organisms such as Chlamydia pneumoniae that have been 8 associated with exacerbations of asthma may also play a part in COPD and have been isolated. ${ }^{19}$

Viral infections are an important trigger of COPD exacerbations. Studies in childhood asthma have shown that viruses, especially rhinovirus (the cause of the common cold), can frequently be detected by polymerase chain reaction ${ }^{20}$ Rhinovirus has not hitherto 
been considered to be of much significance during exacerbations of COPD. In a two year study of 44 patients with chronic bronchitis Stott and colleagues found rhinovirus in $13(14.9 \%)$ of 87 exacerbations. ${ }^{21}$ In a more detailed study of 25 patients with chronic bronchitis who had 116 exacerbations over four years, Gump et al found that only $3.4 \%$ could be attributed to rhinoviruses ${ }^{22}$ In a more recent study of 35 episodes of COPD exacerbations using serological methods and nasal samples for viral culture, little evidence was found for the presence of rhinovirus during COPD exacerbations. ${ }^{23}$ Harper-Owen and colleagues have recently shown that up to one third of COPD exacerbations were associated with viral infections, $75 \%$ of which were found to be caused by rhinoviruses when samples were taken from nasopharyngeal aspirates. ${ }^{2}$ Virally linked exacerbations were associated with symptoms of the common cold and prolonged recovery from exacerbation.

\section{Airway inflammation during COPD exacerbations}

Although it has been assumed that exacerbations of COPD are associated with increased airway inflammation, little information is available on the nature of inflammatory markers as it is difficult to take bronchial biopsy specimens during an exacerbation in patients with moderate to severe COPD. In one study in which biopsy specimens were taken during exacerbations, increased airway eosinophilia was found although the patients studied had only mild COPD ${ }^{25}$ During exacerbations there were more modest increases in neutrophils, $\mathrm{T}$ lymphocytes (CD3), and TNF- $\alpha$ positive cells, while no significant changes were seen in CD4 or CD8 $\mathrm{T}$ cells, macrophages, or mast cells.

As the technique of sputum induction is non-invasive, it allows study of these patients during exacerbations and is a safe and well tolerated technique ${ }^{26}$ Bhowmik and colleagues prospectively followed a cohort of patients in the East London COPD Study and related inflammatory markers in induced sputum to symptoms and physiological parameters both at baseline and during exacerbations ${ }^{27}$ During exacerbations the levels of interleukin (IL)- 6 in induced sputum were increased and, furthermore, IL-6 levels were higher when exacerbations were associated with symptoms of the common cold. Experimental rhinovirus infection has been shown to increase sputum levels of LL-6 in normal subjects and patients with asthma ${ }^{28}{ }^{30}$ However, rises in neutrophil, eosinophil, and IL-8 levels were more variable with exacerbations of COPD and did not reach statistical significance. Patients with COPD already have upregulated levels of airway IL-8 when stabl ${ }^{3}$ because of their high sputum neutrophil load and further increases during exacerbations would be unlikely. Exacerbations of COPD are also associated with less pronounced airway inflammatory responses than asthma ${ }^{32}$ and this may explain the relatively reduced response to steroids seen during exacerbations in patients with COPD compared with asthma 3 3 $^{-37}$ The lack of response to steroids in patients with COPD when stable may also be due to the fact that inflammation in COPD is neutrophilic and is associated with increased numbers of CD 8 T cells. However, during exacerbations viruses may increase levels of eosinophils or other cytokines such as IL-6 and so explain some beneficial steroid responses.

\section{Corticosteroid treatment of COPD exacerbations}

A number of early studies investigated the effect of 궁 corticosteroid treatment during COPD exacerbations. 을 In an early controlled trial in patients with COPD exacerbations and acute respiratory failure, Albert and $\overrightarrow{\overrightarrow{\vec{\omega}}}$ co-workers found that there were larger improvements $\overline{0}$ in pre and post bronchodilator $\mathrm{FEV}_{1}$ in patients treated for the first three days of the hospital admission with $\frac{\bar{\Phi}}{\bar{D}}$ intravenous methylprednisolone than in those treated $\stackrel{\mathbb{Q}}{\Omega}$ with placebo ${ }^{3}$ Another trial found that a single dose of methylprednisolone given within 30 minutes of arrival $\vec{\circ}$ in the accident and emergency department produced no improvement in spirometric parameters after five $\vec{\omega}$ hours and also had no effect on hospital admission rates ${ }^{34}$ However, another study showed that early treatment with steroids could reduce the hospital re- $\underset{x}{x}$ admission rate ${ }^{35}$ A retrospective study of patients of treated with steroids during exacerbations compared is with those not so treated showed that the steroid group $\frac{0}{0}$ had a reduced chance of relapse after treatment ${ }^{36}$

In a randomised controlled trial Thompson and col- is league ${ }^{37}$ gave a nine day tapering dose of prednisolone $\underset{\omega}{\omega}$ or placebo to outpatients presenting with acute ex- 음 acerbations of COPD. Unlike the previous studies, these patients were either recruited from outpatients or from a group of COPD patients that were pre-enrolled and self-reported exacerbations to the study team. Patients $\stackrel{\mathscr{\rho}}{\sim}$ with exacerbations associated with acidosis or pneu- $\tilde{O}$ monia were excluded. Patients in the steroid treated group showed a more rapid improvement in $\mathrm{PaO}_{2}$, alveolar-arterial oxygen gradient, $\mathrm{FEV}_{1}$, peak expiratory flow, and dyspnoea. The steroid treated group also had fewer treatment failures than the placebo group.

In a recent cohort study by Seemungal and col- $\mathbb{D}$ league ${ }^{10}$ the effect of treatment with prednisolone on $\overrightarrow{\overrightarrow{0}}$ COPD exacerbations diagnosed and treated in the com- 3 munity was studied. Exacerbations treated with steroids were more severe and were associated with larger falls in peak flow. The treated exacerbations also had a longer recovery time to baseline for symptoms and peak flow. However, the rate of recovery of peak flow, but not of ${ }_{i}^{x}$ symptoms, was faster in the prednisolone treated group. An interesting finding in this study was that steroids 8 significantly prolonged the median time from the day of onset of the initial exacerbation to the next exacerbation, 욱 from 60 days in the untreated group to 84 days in the patients treated with prednisolone $(p=0.037)$. In contrast, antibiotic therapy had no effect on the time $N$ to the next exacerbation. If short course oral steroid therapy during exacerbations does prolong the time to the next exacerbation, this could be an important way $\omega$ of reducing the frequency of exacerbations in patients with COPD 2

The mechanisms for improving lung function in $\stackrel{\mathbb{P}}{\rightarrow}$ patients treated with steroids during exacerbations may include a reduction in airway inflammation or a decrease $\vec{P}$ in airway oedema, especially as in some studies the $\stackrel{\Phi}{\Phi}$ changes have occurred relatively early after the start of $\stackrel{\mathbb{Q}}{\varrho}$ treatment. Oral steroids have been shown to downregulate ICAM-1, the receptor responsible for virus- 8 epithelial cell interactions, possibly reducing the fre- $\frac{0}{2}$ quency of virus associated COPD exacerbations ${ }^{38}$ However, the study by Seemungal and colleagues was not designed to evaluate the effects of steroid action during COPD exacerbations and further controlled studies are required of the effect of steroids on the interval between exacerbations. 
Introductory articles

In the randomised controlled study reported by Davies and colleague $\beta^{39}$ patients admitted to hospital with COPD exacerbations were randomised to receive oral prednisolone $30 \mathrm{mg}$ once daily or placebo. The difficulty of performing such a study was highlighted by the fact that a total of 245 patients were screened to produce 60 evaluable patients. The main reason for exclusion was previous treatment with oral steroids prior to hospital admission, emphasising the widespread practice of prescribing steroids for COPD exacerbations. Although it may have been expected that this selection would produce study patients with less severe COPD exacerbations, the mean $\mathrm{FEV}_{1}$ of the patients in the prednisolone and placebo groups was $27.4 \%$ predicted and $21.4 \%$ predicted, respectively, confirming recruitment of severely affected patients with COPD. In the prednisolone treated group the $\mathrm{FEV}_{1}$ rose faster until day 5 when a plateau was observed; the post-bronchodilator $\mathrm{FEV}_{1}$ increased by $90 \mathrm{ml} /$ day with a smaller rise of $30 \mathrm{ml} /$ day in the placebo group $(p=0.039)$. Changes in the prebronchodilator and post-bronchodilator $\mathrm{FEV}_{1}$ were similar, which suggests that this was not just an effect on bronchomotor tone but involved faster resolution of airway inflammatory changes or airway wall oedema.

Patients who were acidotic or who developed acidosis during the study period were excluded. Length of hospital stay, analysed on an intention to treat basis, was significantly shorter in patients treated with prednisolone than in the placebo group ( 7 versus 9 days, $\mathrm{p}=0.027$ ). Although this is a relatively small difference, it could represent an important health economic benefit. All the patients were followed up at six weeks with measurement of $\mathrm{FEV}_{1}$ and a quality of life questionnaire. At this time there were no differences in spirometric parameters between the patient groups and health status was similar to that measured at five days after admission. Thus, the benefits of steroid treatment during exacerbations are most obvious in the early part of the exacerbation. However, some exacerbations may require longer recovery times than six weeks for complete resolution. Approximately $32 \%$ of patients in both study groups required further treatment for exacerbations within six weeks of follow up, emphasising the high exacerbation frequency in these patients.

In the second introductory article Niewoehner and colleague ${ }^{40}$ performed a randomised controlled trial of either a two week or eight week course of prednisolone for exacerbations of COPD compared with placebo, in addition to other treatment. The primary end point was treatment failure, including death, need for intubation, readmission, or intensification of treatment. There was no difference between the two and the eight week treatment protocols. The rates of treatment failure were higher in the placebo group (33\% at 30 days) than in the combined two and eight week prednisolone groups $\overrightarrow{\vec{F}}$ $(23 \%, \mathrm{p}=0.04)$. The combined treatment groups also showed a slightly reduced length of hospital stay com- $\frac{\bar{\sigma}}{\sigma}$ pared with the placebo group (8.5 days versus 9.7 days, $\mathrm{p}=0.03)$. As in the study by Davies and colleagues ${ }^{30} \frac{\mathrm{Q}}{8}$ the $\mathrm{FEV}_{1}$ improved faster in the prednisolone treated group, although there were no differences between the groups by two weeks. In contrast, Niewoehner et al $\vec{\circ}$ performed a detailed evaluation of complications and $\overrightarrow{\vec{\omega}}$ found evidence of hyperglycaemia in the steroid treated $\stackrel{\circ}{\circ}$ patients. They also found a trend towards longer hospital $\overrightarrow{\vec{\sigma}}$ stays in the eight week treatment group, together with $\underset{\otimes}{\otimes}$ more exacerbations that required readmission to hos- $x$ pital. They conclude that steroids should be used for $f$ COPD exacerbations in short courses of no more than $\frac{\text { ? }}{0}$ two weeks duration to avoid the risk of complications.

An interesting finding from this study was that, when $\overrightarrow{-}$ a subgroup analysis was performed, steroid treatment is had a more favourable outcome in patients who had $\omega$

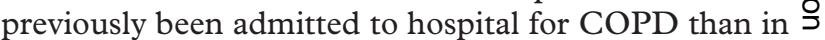
those who had not. This suggests that steroids may be $\vec{\longrightarrow}$ more effective in patients with frequent exacerbations. Bhowmik and colleague ${ }^{26}$ have shown that induced $\frac{0}{\infty}$ sputum IL-6 and IL-8 levels were higher in stable $\vec{N}$ patients with COPD with a history of frequent ex- 8 acerbations than in patients with infrequent ex-. acerbations. Airway IL-6 levels rose further with exacerbations. Patients who have frequent exacerbations have increased airway inflammation and may therefore be expected to have an increased benefit from steroids when they develop an exacerbation.

\section{Conclusions}

The results of both studies described in the introductory articles show that overall benefits in patients with COPD are generally small, with marginal reductions in hospital stay and early increases in spirometric parameters within the first five days of the exacerbation. Neither of these 3 studies showed any longer term benefits and there was no evidence for a reduction in the frequency of ex- 3 acerbations although these studies were not designed 0 to test this particular hypothesis. There is currently no evidence available to support the suggestion that exacerbations contribute to decline in lung function.

\section{LEARNING POINTS}

* Treatment of COPD exacerbations with oral corticosteroids leads to early modest improvements in spirometric parameters and marginal reductions in length of hospital stay

* A two week course of oral prednisolone is as effective as longer courses for exacerbations of COPD

* Oral corticosteroids for exacerbations of COPD can lead to hyperglycaemia in some patients

* There are no long term benefits from using corticosteroids for exacerbations of COPD

* The mechanisms of corticosteroid action during exacerbations may involve faster resolution of airway inflammatory changes and reduction of airway oedema

* Patients with COPD who have a history of frequent exacerbations may achieve the greatest benefit from oral corticosteroids during exacerbations 
Recovery of lung function after an exacerbation is not always complete and steroids may improve recovery, although the studies described in this review were not designed to address this question. The response to steroids was far less than in patients with asthmatic exacerbations, and a two week course of steroids was as effective as an eight week course. Both studies evaluated patients during acute admissions; there is little information available concerning the use of steroids for exacerbations in patients treated in the community, which will obviously be less severe than in those admitted to hospital. There is a trend to move towards supported discharge of patients with COPD exacerbations to avoid hospital admission, and thus it is likely that more steroid courses will be prescribed for exacerbations in the community.

These studies evaluated predictive factors for steroid response and the only interaction observed was the effect of steroid treatment in patients with frequent exacerbations. Thus, patients who have frequent exacerbations may be a subgroup who will benefit more from steroid treatment during exacerbations, whether treated in the community or in hospital. Much more research is required into the mechanisms and treatment of exacerbations of COPD so that the considerable associated morbidity and mortality can be reduced.

1 Osman LM, Godden DJ, Friend JAR, et al. Quality of life and hospital re-admission in patients with chronic obstructive pulmonary disease. Thorax 1997;52:67-71.

2 Seemungal TAR, Donaldson GC, Paul EA et al. Effect of exacerbation on quality of life in patients with chronic obstructive pulmonary disease. Am 7 Respir Crit Care Med 1998;157:1418-22.

3 COPD Guidelines Group of the Standard of Care Committee of the British Thoracic Society. BTS guidelines for the management of chronic obstructive pulmonary disease. Thorax 1997;52(Suppl 5): S1-28.

4 Siafakas NM, Vermiere P, Pride NB, et al. Optimal assessment and management of chronic obstructive pulmonary disease (COPD). Eur Respir 7 1995;8:1398-420.

5 Callahan CM, Cittus RS, Katz BP. Oral corticosteroid therapy for patients with stable chronic obstructive pulmonary disease: a metapatients with stable chronic obstructive pulm
analysis. Ann Intern Med 1991;114:216-23.

6 Keatings VM, Jatakanon A, Worsdell Y, et al. Effects of inhaled and oral glucocorticoids on inflammatory indices in asthma and COPD Am $\mathcal{J}$ Respir Crit Care Med 1997;155:542-8.

7 Culpitt SV, Maziak W, Loukidis S, et al. Effects of high dose inhaled steroids on cells, cytokines and proteases in induced sputum in chronic obstructive pulmonary disease. Am f Respir Crit Care Med 1999;160 1635-9.

8 Rowe $\mathrm{BH}$, Keller JL, Oxman AD. Effectiveness of steroid therapy in acute exacerbations of asthma: a meta-analysis. Am 7 Emerg Med 1992;10:301-10.

9 Okubadejo AA, Jones PW, Wedzicha JA. Quality of life in patients with chronic obstructive pulmonary disease and severe hypoxaemia. Thorax 1996;51:44-7.

10 Seemungal TAR, Donaldson GC, Bhowmik A, et al. Time course and recovery of exacerbations in patients with chronic obstructive pulmonary disease. Am ₹ Respir Crit Care Med 2000 (in press).

11 Reddel HS, Ware S, Marks G, et al. Differences between asthma exacerbations and poor asthma control. Lancet 1999;353:364-9.

12 Tattersfield AE, Postma DS, Barnes PJ, et al. Exacerbations of asthma. Am f Respir Crit Care Med 1999;160:594-9.

13 Donaldson GC, Seemungal T, Jeffries DJ, et al. Effect of environmenta temperature on symptoms, lung function and mortality in COPD patients. Eur Respir f 1999;13:844-9
14 Anderson HR, Limb ES, Bland JM, et al. Health effects of an air pollution episode in London, December 1991. Thorax 1995;50:118893.

15 Zalacain R, Sobradillo V, Amilibia J, et al. Predisposing factors to bacterial colonization in chronic obstructive pulmonary disease. Eur Respir F 1999;13:343-8.

16 Gompertz S, OBrien C, Leung B, et al. The relationship between bacterial load and neutrophilic bronchial inflammation in stable COPD. Thorax 1999;54:A1.

17 Monso E, Rosell A, Bonet G, et al. Risk factors for lower airway bacterial colonization in chronic bronchitis. Eur Respir F 1999;13:338-42.

18 Wilson R. Bacterial infection and chronic obstructive pulmonary disease. Eur Respir f 1999;13:233-5.

19 Harper-Owen R, Seemungal TAR, Johnston SL, et al. Role of Chlamydia pneumoniae in COPD exacerbations. Am $\mathcal{F}$ Respir Crit Care Med 2000 (in press)

20 Johnston SL, Pattemore PK, Sanderson G, et al. Community study of ڤొ the role of viral infections in exacerbations of asthma in 9-11 year the role of viral infections in exacerb

21 Stott EJ, Grist NR, Eadie MB. Rhinovirus infections in chronic bronchitis: isolation of eight possible new rhinovirus serotypes. f Med Microbiol 1968;109:117.

22 Gump DW, Phillips CA, Forsyth BR. Role of infection in chronic bronchitis. Am Rev Respir Dis 1976;113:465-73.

23 Philit F, Etienne J, Calvet A, et al. Infectious agents associated with exacerbations of chronic obstructive pulmonary disease and attacks of asthma. Rev Mal Respir 1992;9:191-6.

24 Harper-Owen R, Seemungal TAR, Bhowmik A, et al. Virus and Chla- G mydia isolation in COPD exacerbations. Eur Respir f 1999;14(Suppl is 30): $47 \mathrm{~s}$.

25 Saetta M, Di Stefano A, Maestrelli P, et al. Airway eosinophilia in chronic bronchitis during exacerbations. Am $\mathcal{F}$ Respir Crit Care Med 1994;150:1646-52.

26 Bhowmik A, Seemungal TAR, Sapsford RJ, et al. Comparison of spon- is taneous and induced sputum for investigation of airway inflammation $\mathrm{N}$ in chronic obstructive pulmonary disease. Thorax 1998;53:953-6.

27 Bhowmik A, Seemungal TAR, Sapsford RJ, et al. Relation of sputum 윽 inflammatory markers to symptoms and physiological changes at COPD exacerbations. Thorax 2000;55:114-200.

28 Fraenkel DJ, Bardin PG, Sanderson G, et al. Lower airways inflammation during rhinovirus colds in normal and in asthmatic subjects. Am $\mathcal{F}$ Respir Crit Care Med 1995;151:879-86.

29 Grunberg K, Smits HH, Timmers MC, et al. Experimental rhinovirus $\stackrel{\mathscr{O}}{\rightarrow}$ 16 infection: effects on cell differentials and soluble markers in sputum $N$ of asthmatic subjects. Am f Respir Crit Care Med 1997;156:609-16.

30 Fleming HE, Little EF, Schnurr D, et al. Rhinovirus-16 colds in healthy and asthmatic subjects. Am F Respir Crit Care Med 1999;160:100-8.

31 Keatings VM, Collins PD, Scott DM, et al. Differences in interleukin8 and tumour necrosis factor in induced sputum from patients with chronic obstructive pulmonary disease and asthma. Am f Respir Crit chronic obstructive pulmonar
Care Med 1996;153:530-4

32 Pizzichini MMM, Pizzichini E, Clelland, et al. Sputum in severe exacerbations of asthma: kinetics of inflammatory indices after prednisone treatment. Am f Respir Crit Care Med 1997;155:1501-8.

33 Albert RK, Martin TR, Lewis SW. Controlled clinical trial of methylprednisolone in patients with chronic bronchitis and acute respiratory insufficiency. Ann Intern Med 1980;92:753-8.

34 Emerman CL, Connors AF, Lukens TW, et al. A randomised controlled trial of methylprednisolone in the emergency treatment of acute exacerbations of chronic obstructive pulmonary disease. Chest 1989; 95:563-7.

35 Bullard MJ, Liaw SJ, Tsai YH, et al. Early corticosteroid use in acute exacerbations of chronic airflow limitation. Am f Emerg Med 1996; 14:139-43.

36 Murata GH, Gorby MS, Chick TW, et al. Intravenous and oral corticosteroids for the prevention of relapse after treatment of decompensated COPD. Chest 1990;98:845-9.

37 Thompson WH, Nielson CP, Carvalho P, et al. Controlled trial of oral prednisolone in outpatients with acute COPD exacerbation. Am $\mathcal{F}$ (154:407-12.

38 Terajima M, Yamaya $M$, Sekizawa $S$, et al. Rhinovirus infection of $\mathrm{O}$ primary cultures of human tracheal epithelium: role of ICAM-1 and IL-1 beta. Am 7 Physiol 1997;273: L749-59.

9 Davies L, Angus RM, Calverley PMA. Oral corticosteroids in patients admitted to hospital with exacerbations of chronic obstructive pul-
monary disease: a prospective randomised controlled trial. Lancet $\mathrm{N}$ 1999;354:456-60.

40 Niewoehner DE, Erbland ML, Deupree RH, et al Effect of systemic N glucocorticoids on exacerbations of chronic obstuctive pulmonary disease. N Engl f Med 1999;340:1941-7.

㑾

